\title{
Comparative study between classical methods and genetic algorithms for sizing remote PV systems
}

\author{
S. Makhloufi ${ }^{1}$
}

Received: 19 March 2014/Accepted: 26 March 2015/Published online: 15 April 2015

(C) The Author(s) 2015. This article is published with open access at Springerlink.com

\begin{abstract}
Uncertain renewable energy supplies, load demands and the non-linear characteristics of some components of photovoltaic (PV) systems make the design problem not easy to solve by classical optimization methods, especially when relevant meteorological data are not available. To overcome this situation, modern methods based on artificial intelligence techniques have been developed for sizing PV systems. However, simple methods like worst month method are still largely used in sizing simple PV systems. In the present study, a method for sizing remote PV systems based on genetic algorithms has been compared with two classical methods, worst month method and loss of power supply probability (LPSP) method. The three methods have been applied to a PV lighting system with orientation due south and inclination angles between $0^{\circ}$ and $90^{\circ}$ in Adrar city (south Algeria). Because measured data for the chosen location were not available, a year of synthetic hourly meteorological data of this location, generated by PVSYST software, have been used in the simulation. Genetic algorithms and worst month methods give results close to each other between $0^{\circ}$ and $60^{\circ}$ but the system is largely oversized by the worst month method when the tilted angle is over $60^{\circ}$. The results obtained by LPSP method show that the system is very undersized. Hence, a proposition has been made to improve results obtained by this method.
\end{abstract}

Keywords Cost - Genetic algorithms - Lighting - LPSP . Optimization $\cdot$ Photovoltaic $\cdot$ Worst month

S. Makhloufi

makhlofi_s@yahoo.fr

LEESI Laboratory, University of Adrar, Adrar, Algeria

\section{Introduction}

Conventional methodologies (empirical, analytical, numerical, hybrid, etc.) are used for sizing photovoltaic (PV) systems, especially when the required weather data (irradiance, temperature, humidity, clearness index, wind speed, etc.) and the information concerning the location of PV system are available [1-4]. These methods present a good solution for sizing PV systems under the above conditions. However, such techniques cannot be used for sizing PV systems where the required data are not available. Moreover, the majority of the above methods need long-term meteorological data, such as total solar irradiance, air temperature, and wind speed, for their operations. To overcome this situation, newer methods have been developed for sizing the parameters for PV systems based on artificial intelligence techniques [5]. However, these methods require complex implementation and powerful calculators to reduce time calculation which makes simple methods, like worst month method, still largely used in sizing simple remote PV systems.

A wide range of literature is available in this area. Chen [6] proposes a sizing procedure based on the long-term trend of the observed extremes of solar radiation. In [7] the sizing and designing of a standalone photovoltaic electricity generation system for a small household load performed using the locally acclimatized simulation program is discussed. In [8] a hybrid approach, combining analytical sizing equations with long-term performance, for an optimal design of a standalone PV battery system is proposed. In [9] after the sizing of PV generator in conventional irradiation and ambient temperature conditions, the proper battery capacity has been estimated with iterative simulations. Becherif et al. [10] deal with the design, modeling, sizing and control of a photovoltaic standalone Home to 
Vehicle (HV) application that can fully charge the Battery Electrical Vehicles (EV) overnight at home. Brenna et al. [11] instead deals with the capability of PV and EV in gridconnected systems based on daily average solar irradiance as a function of the site coordinates. In [12] a methodology for optimum design of solar array and battery bank for a solar array-exclusive standalone photovoltaic system using energy balance concept is presented. The constraint of system cost function based on loss of power supply probability (LPSP) has been implemented using genetic algorithms (GA). In [13] one optimum sizing method based on genetic algorithm, for solar lighting system with battery banks, was recommended. In [14] the authors study the sizing and economic optimization of a standalone photovoltaic-wind hybrid system with storage batteries, installed in a semi-arid region of Algeria supplying a farm. Two methods were developed. The first method is based on the average annual monthly values in which the size of photovoltaic and wind generators was determined from the average monthly contribution of each component. In the second method, the determination of these two system components size is based on the worst month. Zaninelli and Leva [15] introduces hybrid photovoltaic-wind-diesel generation systems supplying a remote power load. A cost investment valuation is performed on a real plant showing the effect of sustainable economical saving. In [16] a cost investment evaluation is performed on a real plant showing the effect and the weight of sustainability economical saving. The possibility to introduce a fuel cell generation device is also investigated. Simonov et al. [17] discusses the role of evolutionary computational tools and some issues related to the variability and uncertainty in the operations where PV plants are potentially fully connected to the power grid in a future scenario.

Recently, using PV lighting systems has been considerably increased in Algeria. This is motivated by the enormous potential of PV energy, especially in the south. For example, in Adrar city $\left(27.51^{\circ} \mathrm{N}, 0.17^{\circ} \mathrm{W}\right)$, the annual mean insolation incident on a horizontal surface equals to $5.68 \mathrm{kWh} / \mathrm{m}^{2} /$ day [18]. Consequently developing powerful methods to optimum sizing of these systems becomes very necessary.

In the present study, a method for sizing remote PV systems based on GA [19] has been compared with two classical methods, worst month method [1] and LPSP method [20]. The three methods have been applied to a PV lighting systems with orientation due south and inclination angles between $0^{\circ}$ and $90^{\circ}$ in Adrar city (south Algeria).

Because measured data for the chosen location were not available, a year of synthetic hourly meteorological data of this location, generated by PVSYST software, have been used in the simulation.

The PV lighting system studied is shown in Fig. 1.

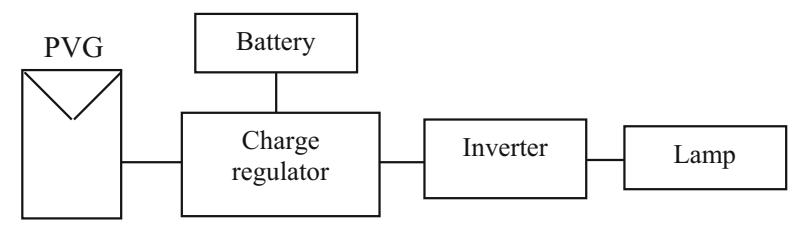

Fig. 1 Studied system

\section{Mathematical modeling}

\section{Photovoltaic array output modeling}

The "four-parameter" equivalent circuit model that considers a PV cell as an "ideal" irradiance-dependent current source in parallel with a diode was used to model the PV module [21]. The four parameters are module photocurrent at reference conditions $\left(I_{\mathrm{L}}\right.$, ref $)$, diode reverse saturation current at reference conditions $\left(I_{0}\right.$, ref), empirical diode PV curve fitting factor $\left(d_{1}\right)$, and module series resistance $\left(R_{\mathrm{S}}\right)$ [22]. The total current $(I)$ is calculated as follows [23]:

$I=I_{\mathrm{L}}-I_{0}\left[\exp \left(\frac{q}{d_{1} k T_{\mathrm{c}}}\left(V+I R_{\mathrm{s}}\right)\right)-1\right]$

The values of parameters $d 1$ and $R \mathrm{~s}$ are fixed for a given PV cell. The photocurrent (IL) is linearly proportional to the incident irradiance:

$I_{\mathrm{L}}=I_{\mathrm{L}, \text { ref }} \frac{I_{T}}{I_{T, \text { ref }}}$

where $I_{\mathrm{L}, \text { ref }}$ is the photocurrent at the reference conditions and $I_{T}$ and $I_{T, \text { ref }}$ represent incident irradiance at any time and reference insolation, respectively, where the reference insolation is equal to $1000 \mathrm{~W} / \mathrm{m}^{2}$.

The reverse saturation current $\left(I_{0}\right)$ is expressed in terms of material characteristics and PV module temperature $\left(T_{c}\right)$ :

$I_{0}=I_{0, \text { ref }}\left(\frac{T_{\mathrm{c}}}{T_{\mathrm{c}, \text { ref }}}\right)^{3} \exp \left[\frac{q \varepsilon}{d k}\left(\frac{1}{T_{\mathrm{c}, \text { ref }}}-\frac{1}{T_{\mathrm{c}}}\right)\right]$

where $d$ is equal to $d_{1} / n_{\mathrm{s}} ; n_{\mathrm{s}}$ is the number of cells in the module connected in series; $\varepsilon$ is the semiconductor bandgap energy; and $I_{0, \text { ref }}$ and $T_{\mathrm{c}, \text { ref }}$ are reverse saturation current and module temperature, respectively, at reference conditions.

The values of the parameters $I_{\mathrm{L}, \mathrm{ref}}, I_{0, \text { ref }}, d_{1}$ and $R_{\mathrm{S}}$ have been calculated in [24] and are given in Table 1.

The photovoltaic generator (PVG) reference characteristic parameters used in the study are shown in Table 1.

\section{Storage modeling}

Several models are proposed in the literature for battery storage modeling. A simple model proposed in [25] has 
Table 1 PV module characteristic parameters

\begin{tabular}{ll}
\hline Parameter & Value \\
\hline Module short-circuit current at reference conditions & $3.45 \mathrm{~A}$ \\
Module open-circuit voltage at reference conditions & $43.5 \mathrm{~V}$ \\
Temperature at reference conditions & $298 \mathrm{~K}$ \\
Irradiance at reference conditions & $1000 \mathrm{~W} / \mathrm{m}^{2}$ \\
Maximum power point voltage at reference conditions & $35.0 \mathrm{~V}$ \\
Maximum power point current at reference conditions & $3.15 \mathrm{~A}$ \\
Semiconductor band gap & $1.12 \mathrm{eV}$ \\
Number of cells in the module connected in series & 72 \\
Module photocurrent at reference conditions & $3.45 \mathrm{~A}$ \\
Diode reverse saturation current at reference & $2.86 .10-6 \mathrm{~A}$ \\
conditions & 120 \\
Empirical diode PV curve fitting factor & $0.2421 \Omega$ \\
Module series resistance & \\
\hline
\end{tabular}

been chosen. This model allows calculating storage capacity according to the produced power by PV generator and the load. This model does not consider temperature effect.

During the charge, battery capacity is described by the following equation:

$$
\begin{aligned}
C_{\mathrm{bat}}(t)= & \operatorname{Min}\left(C_{\mathrm{N}}, C_{\mathrm{bat}}(t-1) \cdot(1-\sigma)\right. \\
& \left.+\left(P_{\mathrm{pv}}(t)-\frac{P_{\mathrm{c}}(t)}{\eta_{\text {inv }}}\right) \cdot \eta_{\mathrm{bat}}\right)
\end{aligned}
$$

where $C_{\mathrm{N}}$ nominal capacity of the battery (Wh), $C_{\text {bat }}(t)$ battery capacity at $t$ time, $C_{\mathrm{bat}}(t-1)$ battery capacity at $t-1$ time, $\sigma$ self-discharge rate, $P_{\mathrm{pv}}(t)$ produced power by the PV generator at $t$ time, $P_{\mathrm{c}}(t)$ charge demand at $t$ time, $\eta_{\text {inv }}$ DC/AC inverter efficiency, $\eta_{\text {bat }}$ battery efficiency.

During the discharge, battery capacity is described by the following equation:

$$
\begin{aligned}
C_{\mathrm{bat}}(t)= & \operatorname{Max}\left(C_{\mathrm{N}} \cdot(1-\mathrm{DOD}), C_{\mathrm{bat}}(t-1) \cdot(1-\sigma)\right. \\
& \left.+\left(P_{\mathrm{pv}}(t)-\frac{P_{\mathrm{c}}(t)}{\eta_{\mathrm{inv}}}\right)\right)
\end{aligned}
$$

where DOD is the depth of discharge.

Since the studied system is a lighting system, some particularities must be considered. During the charge phase, i.e. during the daylight, there is no charge demand, so $P_{\mathrm{c}}(t)$ is equal to zero. During discharge phase, i.e. during the night, $\mathrm{PV}$ generator does not produce any power, so $P_{\mathrm{pv}}(t)$ is equal to zero. Moreover, load is constant because it is a lamp. Therefore, charge and discharge models became:

$$
C_{\text {bat }}(t)=\operatorname{Min}\left(C_{\mathrm{N}}, C_{\text {bat }}(t-1) \cdot(1-\sigma)+\left(P_{\mathrm{pv}}(t)\right) \cdot \eta_{\text {bat }}\right)
$$

for charge and:

$$
\begin{aligned}
C_{\text {bat }}(t)= & \operatorname{Max}\left(C_{\mathrm{N}} \cdot(1-\mathrm{DOD}), C_{\mathrm{bat}}(t-1)\right. \\
& \left.\cdot(1-\sigma)-\left(\frac{P_{\mathrm{c}}}{\eta_{\text {inv }}}\right)\right)
\end{aligned}
$$

for discharge.

In this study $\eta_{\mathrm{c}}$ and $\eta_{\text {bat }}$ have been taken equal to $0.9 ; \sigma$ has been taken equal to zero.

\section{Meteorological data computation}

Monthly meteorological data available on the NASA Web site [18] have been used for generating hourly synthetic meteorological data (horizontal global irradiance and ambient temperature) with the aid of PVSYST software [26].

\section{Module temperature}

To determine module temperature, a simple equation has been developed in [21] using module ambient temperature and incident insolation data. The correlation equation is given as follows:

$T_{C}=T_{A}+0.031 I_{T}$

\section{Predicting hourly solar irradiance on inclined surface}

In many sites, at best, only global irradiances on horizontal planes are available. Because most systems using solar energy are tilted, these data are clearly insufficient. A number of models to estimate global irradiance on an inclined surface, from the irradiance on a horizontal surface, are available. However, these models require information at the same time on the global and the direct or diffuse irradiance on a horizontal surface. In [27], two models requiring only the global irradiance on horizontal planes as input parameter were developed. The present work uses the model given in Eq. 9, which yields better results:

$I_{T, \beta}=I_{\mathrm{G}}\left(0.1+\frac{\rho}{2}+\left(0.1-\frac{1}{2} \rho\right) \cos \beta+0.8\left(\cos \theta / \cos \theta_{z}\right)\right)$

where $I_{T, \beta}$ total irradiance received on a tilted surface, $I_{\mathrm{G}}$ the horizontal global irradiance, $\theta_{z}$ zenith angle calculated by [28]:

$\cos \theta_{z}=\sin \delta \sin \phi+\cos \delta \cos \phi \cos \omega$

$\delta$ declination of day $D$ calculated by [29]: 


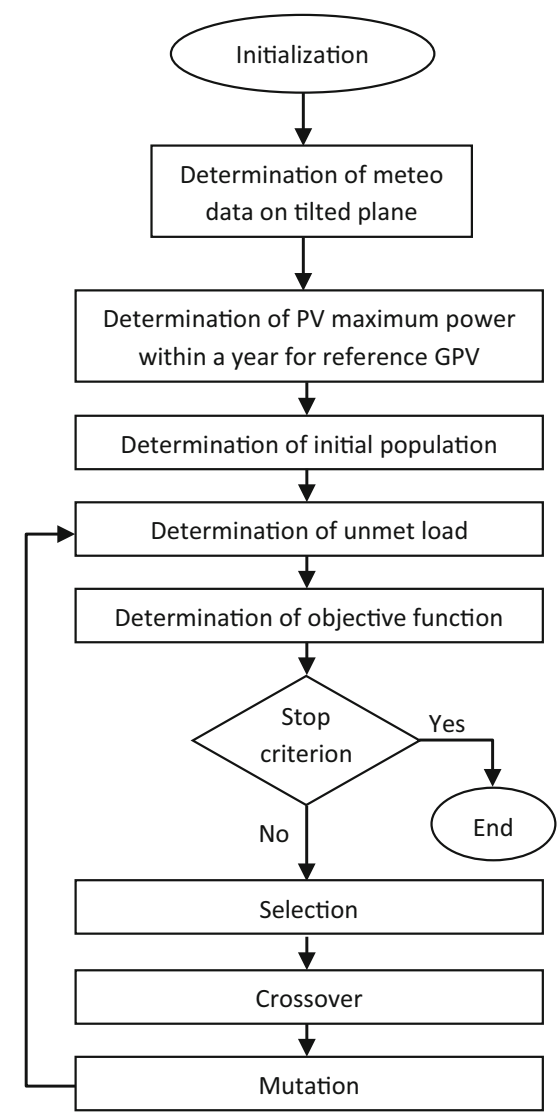

Fig. 2 Flowchart of the method

$\delta(D)=0.4093 \sin \left(2 \pi \frac{D-81}{365}\right)$

$\rho$ albedo (in this work, the value of albedo have been taken constant and is equal to 0.2), $\phi$ geographic latitude, $\omega$ hour angle, and $\theta$ angle of incidence for an arbitrarily inclined surface oriented toward the equator calculated by the following:

$\cos \theta=\sin \delta \sin (\phi-\beta)+\cos \delta \cos (\phi-\beta) \cos \omega$

\section{Genetic algorithms method}

The flowchart of this method is shown in Fig. 2.

The algorithm works with a Boolean vector containing the PVG pick power correction coefficient $\left(k_{1}\right)$ and battery nominal capacity correction coefficient $\left(k_{2}\right)$. The algorithm uses $N_{\text {pop }}$ vectors $\left(k_{1}, k_{2}\right)$.

By determining $k_{1}$, PVG optimum peak power has been obtained using Eq. 14. Coefficient $k_{1}$ has been used also to approximate the maximum power produced by the PVG each hour during the year by multiplying the power of the reference PVG, calculated once a time at the beginning of the program, by that coefficient. This is a good approximation that allows avoiding recalculating maximum power for each element of the vector, so the method became faster.

By the same manner, determining $k_{2}$ allows to obtain battery capacity using Eq. 15 .

\section{Objective function}

The objective function to be minimized includes the following costs:

- Cost of PV panel acquisition

- Cost storage battery acquisition

- Cost of unmet load.

Costs of the other system components have been considered as constant and so omitted in the objective function because they have no effect on the behavior of the results. Hence the objective function is as follows:

$f f=N_{\mathrm{ul}} \cdot C_{\mathrm{ul}}+P_{\mathrm{P}} \cdot C_{\mathrm{GPV}}+C_{\mathrm{N}} \cdot C_{\mathrm{Bat}}$

where $N_{\mathrm{ul}}$ unmet load (number of hours), $C_{\mathrm{ul}}$ cost of $1 \mathrm{~h}$ of unmet load (Euro), $P_{\mathrm{P}} \mathrm{PV}$ generator peak power $(\mathrm{Wp})$, $C_{\mathrm{GPV}}$ one $\mathrm{PV}$ generator Wp cost, $C_{\mathrm{N}}$ battery nominal capacity (Wh), $C_{\mathrm{Bat}}$ one battery Wh cost.

Cost of unmet load should be taken sufficiently high, this will lead to a very large value of the term $N_{\mathrm{ul}} \cdot C_{\mathrm{ul}}$; so the only solution to minimize the objective function is to enforce $N_{\mathrm{ul}}$ to be equal to zero (because this value is admissible). This ensures that we obtain a system with a total autonomy without using a multi-objective optimization.

$P_{\mathrm{P}}$ and $C_{\mathrm{N}}$ are determined as follows:

$P_{\mathrm{P}}=k_{1} \cdot P P_{\mathrm{r}}$

$C_{\mathrm{N}}=k_{2} \cdot C N_{\mathrm{r}}$

where $P P_{\mathrm{r}}$ and $C N_{\mathrm{r}}$ are references of $\mathrm{PV}$ generator peak power and battery nominal capacity, respectively. In this study they have been taken equal to $110 \mathrm{Wp}$ and $1000 \mathrm{Wh}$, respectively.

$k_{1}$ and $k_{2}$ are the correction coefficients determined by GA to optimize system cost.

The main objective of this study is comparing performance of the methods under different tilt angles, so contribution of $O$ and $M$ costs, interest rate, inflation rate etc. to the objective function has been omitted.

\section{Method description}

The method has been implemented in the following way:

First, the parameters used in the optimization are set (see Table 1). Then the irradiation on a tilted surface is calculated using the model described above. The irradiation is 
Table 2 Worst month of each tilt angle

\begin{tabular}{llll}
\hline Tilt angle $\left(^{\circ}\right)$ & Worst month & $\begin{array}{l}\text { Mean daily } \\
\text { global irradiation } \\
\left(\mathrm{Wh} / \mathrm{m}^{2} \text {.day) }\right.\end{array}$ & Mean daily charge (Wh/day) \\
\hline 0 & December & 3315.0 & 432.6 \\
15 & December & 4258.8 & 432.6 \\
30 & December & 4877.6 & 432.6 \\
45 & December & 5225.2 & 432.6 \\
60 & December & 5211.6 & 432.6 \\
75 & July & 2809.6 & 340.6 \\
90 & June & 1281.2 & 324 \\
\hline
\end{tabular}

calculated with a step time of 1 hour. The irradiation during a year is applied to the model of a $110 \mathrm{Wp}$ PVG to determine the PVG maximum power $\left(P_{\max 110}(t)\right)$ produced during every hour of the year. To determine the optimum PV peak power, the $110 \mathrm{Wp}$ PVG is used as a reference, then corrected by the coefficient $k_{1}$. After that, $N_{\text {pop }}$ vectors are obtained randomly. These vectors have been described above, each one representing a possible configuration of PVG peak power and battery capacity. For each vector, the maximum power $\left(k_{1} \cdot P_{\max 110}(t)\right)$ is applied to the storage model to determine the unmet load parameter $N_{\mathrm{ul}}$. In the model of charge described in Eq. 6, $P_{\mathrm{pv}}(t)$ is substituted by " $k_{1} P_{\max 110}(t)$ ". As mentioned above, this is a good approximation to obtain faster method. The objective function is evaluated for each vector. Best vectors (fittest) have a greater probability of reproducing themselves, crossing with other vectors. In each cross of two vectors, two new vectors are obtained (descendants).

The descendants are evaluated and the best of them replace the worst individuals of the previous generation (iteration).

To find the optimal solution and not to stay in local minimal, some solutions randomly change some of their components (mutation). The mutations can affect the change of a bit of $k_{1}$ or $k_{2}$. The individuals (vectors) obtained from reproduction and mutation are evaluated, making the next generation.

The process continues until a determined number of generations have been evaluated.

\section{Worst month method}

For this method, peak power of the PVG and battery nominal capacity are determined as follows:

$$
\begin{gathered}
P_{\mathrm{P}}=\frac{E_{\mathrm{d}}}{K t \cdot \eta_{\mathrm{bat}} \cdot I_{\mathrm{rd}}} \\
C_{N}=\frac{E_{\mathrm{d}} \cdot D}{\eta_{\text {inv }} \cdot D} \text { DOD }
\end{gathered}
$$

where $E_{d}$ daily mean demand during the worst month, $K t$ temperature correction coefficient of the PVG (0.67), $\eta_{\text {bat }}$ battery efficiency (0.9), $I_{\mathrm{rd}}$ daily mean irradiation on tilted plane of the worst month, $D$ number of days of autonomy, $\eta_{\text {inv }}$ DC/AC inverter efficiency (0.9), DOD dept of discharge (0.5).

For each tilted angle, the worst month is determined by calculating the fraction $I_{\mathrm{rd}} / E_{\mathrm{d}}$ for the twelve months. The worst month correspond to the lowest value of this fraction.

Table 2 shows the worst month of each tilted angle and the corresponding data.

System cost for this method is calculated as follows:

$\cos t=P_{\mathrm{P}} \cdot C_{\mathrm{GPV}}+C_{\mathrm{N}} \cdot C_{\mathrm{Bat}}$

This equation is the same as Eq. 13 but the term of unmet load $N_{\mathrm{ul}} \cdot C_{\mathrm{ul}}$ is eliminated.

Lowest cost of the system has been obtained by searching the lowest autonomy duration that allows nonunmet load. This duration has been obtained by trial and error process.

This method has been implemented as follows:

First, autonomy duration is chosen, and then PVG and Battery capacities are calculated using Eqs. 16 and 17. Then, $k_{1}$ and $k_{2}$ are calculated based on Eqs. 14 and 15 . These values are applied to the storage model to calculate unmet load with the same manner as for GA method.

If unmet load is zero the autonomy duration is decremented and the process continues until unmet load became non-zero. If unmet load is non-zero the autonomy duration is incremented and the process continues until unmet load became zero.

\section{LPSP method}

To make results obtained more accurate, a second classical method has been employed in this work. This method has been proposed in [20]. Unlike to the two above methods, that one uses daily data for PV system sizing. First the daily energy output of the solar array is calculated by: 


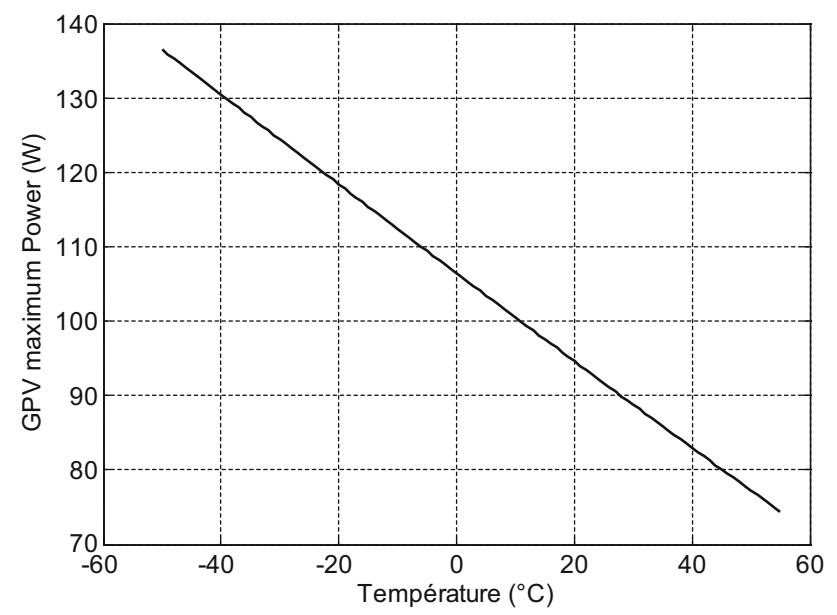

Fig. 3 Maximum power with respect to ambient temperature

$P_{\mathrm{pv}}=P_{\mathrm{pv} \max } *\left[1+*\left(T_{c}-25\right)\right] * \mathrm{PSHs} * \eta_{\mathrm{c}} * \eta_{0}$

where $P_{\mathrm{pv} \text { max }}$ is the maximum power output of the solar array under a solar radiation of $1000 \mathrm{~W} / \mathrm{m}^{2}$. $\rho$ is the negative temperature coefficient of power with respect to solar cell temperature; this coefficient is the slop of the line represented in Fig. 3. This curve has been obtained using the model described in Eq. 1. $\eta_{\mathrm{c}}$ and $\eta_{0}$ are the factors representing connection loses and other loses such as those caused by accumulative dust for example. In this study, these factors have not been considered. PSHs is the peak sun hours equivalent to the length of time in hours at a solar radiation level of $1000 \mathrm{~W} / \mathrm{m}^{2}$. The charge/discharge model used here is the same one described in "Storage modeling". However, time step is not one hour but one day.

The loss of power supply probability (LPSP) is adopted in [20] to describe reliability of power supply to load. It is defined here as

LPSP $=\frac{\sum_{n=1}^{N} \operatorname{LPS}(n)}{\sum_{n=1}^{N} E_{\mathrm{L}}(n)}$

Where $E_{\mathrm{L}}(n)$ is the load demand on day $n$; and $\operatorname{LPS}(n)$ is the loss of energy supply on day $n$ which has been expressed in [20] as:

$\operatorname{LPS}(n)=E_{\mathrm{L}}(n)-\left(E_{\mathrm{pv}}(n)+C_{\mathrm{bat}}(n-1)-C_{\mathrm{bat} \min }\right) * \eta_{\mathrm{inv}}$

For a desired LPSP different size combinations of solar array and battery size can meet the given load demand. Optimum combination is obtained by minimizing Eq. 18.

\section{Meteorological data}

The Insolation Incident on a horizontal surface (kWh/ $\mathrm{m}^{2}$ /day) for Adrar is shown in Table 3 [19]. These data have been used for generating hourly synthetic
Table 3 Insolation incident on a horizontal surface $\left(\mathrm{kWh} / \mathrm{m}^{2} /\right.$ day $)$ for Adrar

\begin{tabular}{|c|c|c|c|c|c|c|}
\hline Jan & Feb & Mar & & Apr & May & Jun \\
\hline 3.68 & 4.74 & 5.90 & & 6.84 & 7.32 & 7.70 \\
\hline Jul & Aug & Sep & Oct & Nov & Dec & Ann \\
\hline 7.45 & 6.96 & 5.86 & 4.60 & 3.83 & 3.32 & 5.68 \\
\hline
\end{tabular}

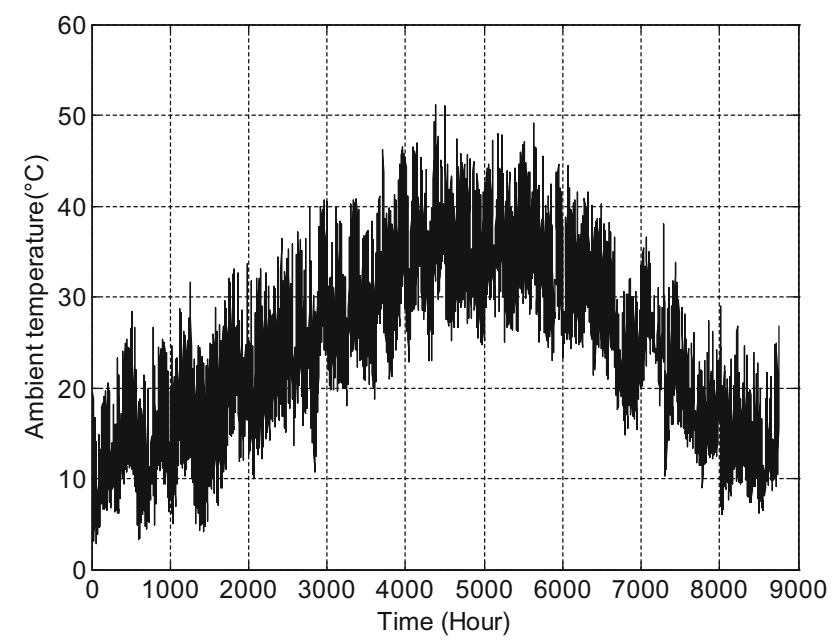

Fig. 4 Ambient temperature for Adrar

meteorological data (horizontal global irradiance and ambient temperature) with the aid of PVSYST software.

Figures 4 and 5 show the synthetic meteorological data generated by PVSYS for Adrar located in Southwest Algeria $\left(27.51^{\circ} \mathrm{N}, 0.17^{\circ} \mathrm{W}\right)$.

\section{Load profile}

Figure 6 shows the daily load profile during a year. Since the studied system is a lighting system, the demand is present during the night. In this study the night is considered when the horizontal global irradiation is less than $50 \mathrm{~W} / \mathrm{m}^{2}$.

\section{Results}

Using the three methods described above, a photovoltaic lighting system located in Adrar (Algeria) has been sized. The three methods have been implemented using Matlab software. The parameters used for the GA method are the following:

The crossover rate is 0.8 , the mutation rate is 0.1 , number of generations is 100 and number of individuals per generation is 100 . 


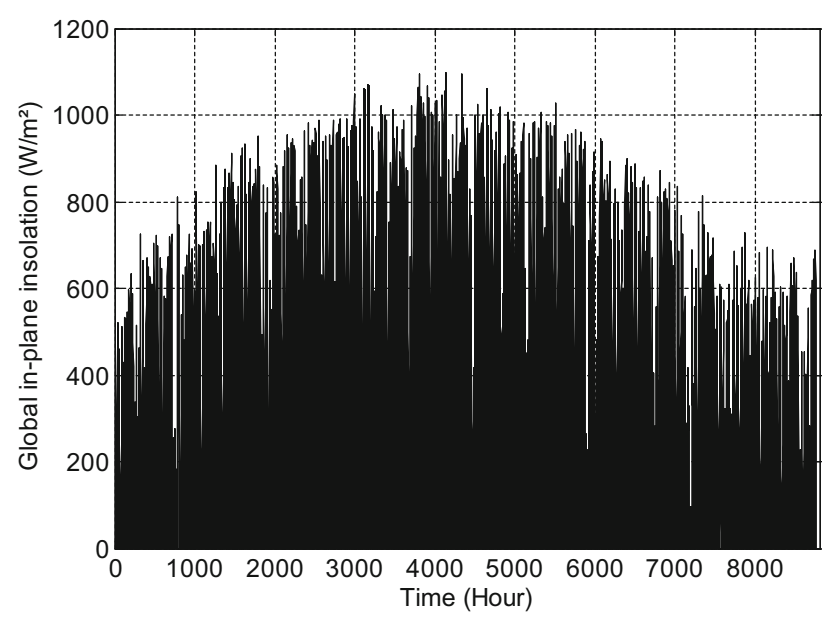

Fig. 5 Global in-plane insolation for Adrar

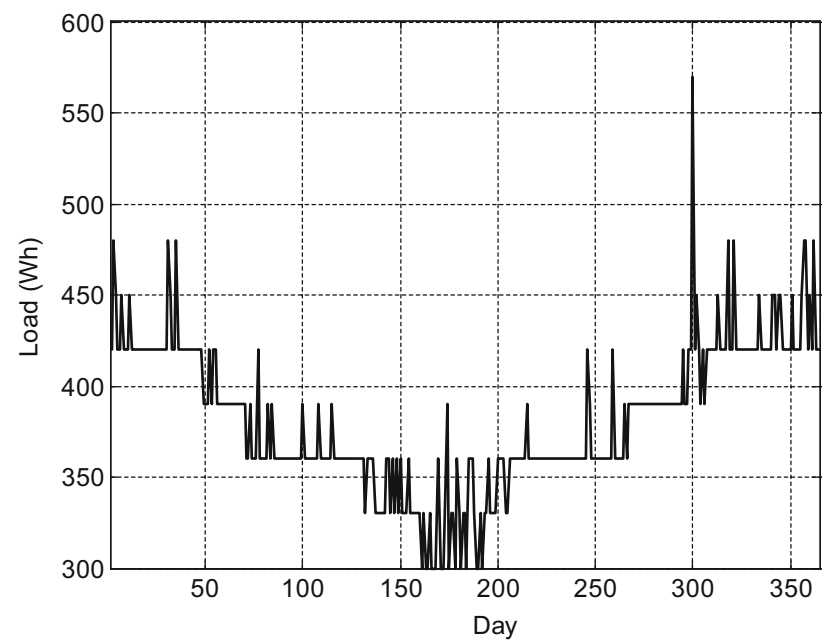

Fig. 6 Load profile

Table 4 GA method results

\begin{tabular}{|c|c|c|c|}
\hline \multirow[b]{2}{*}{$\begin{array}{l}\text { Tilt angle } \\
\left({ }^{\circ}\right)\end{array}$} & \multicolumn{3}{|l|}{ GA method } \\
\hline & $\begin{array}{l}\text { PV generator peak } \\
\text { power }(\mathrm{Wc})\end{array}$ & $\begin{array}{l}\text { Battery capacity } \\
\text { (Wh) }\end{array}$ & $\begin{array}{l}\text { System } \\
\text { cost }(€)\end{array}$ \\
\hline 0 & 202 & 2789 & 1203 \\
\hline 15 & 155 & 2859 & 1103 \\
\hline 30 & 135 & 2875 & 1054 \\
\hline 45 & 126 & 2899 & 1041 \\
\hline 60 & 135 & 2891 & 1060 \\
\hline 75 & 212 & 2408 & 1133 \\
\hline 90 & 499 & 2250 & 1810 \\
\hline
\end{tabular}

The cost of $1 \mathrm{Wp}$ of the PVG has been taken constant and equal to $2.5 €$, the cost of $1 \mathrm{Wh}$ of the battery capacity $0.25 €[30,31]$ and the depth of discharge (DOD) $50 \%$.
Table 5 Worst month method results

\begin{tabular}{lllll}
\hline \multicolumn{4}{l}{ Worst case conditions method } \\
\cline { 2 - 5 } $\begin{array}{l}\text { Tilt } \\
\text { angle } \\
\left({ }^{\circ}\right)\end{array}$ & $\begin{array}{l}\text { PV generator } \\
\text { peak power } \\
(\text { Wc) }\end{array}$ & $\begin{array}{l}\text { Battery } \\
\text { capacity } \\
\text { (Wh) }\end{array}$ & $\begin{array}{l}\text { System } \\
\text { cost }(€)\end{array}$ & $\begin{array}{l}\text { Autonomy } \\
\text { duration used } \\
\text { (days) }\end{array}$ \\
\hline 0 & 217 & 2699 & 1218 & 2.8 \\
15 & 169 & 2796 & 1122 & 2.9 \\
30 & 148 & 2757 & 1059 & 2.9 \\
45 & 138 & 2796 & 1044 & 2.9 \\
60 & 138 & 2892 & 1069 & 3 \\
75 & 202 & 4555 & 1644 & 6 \\
90 & 421 & 7148 & 2841 & 9.9 \\
\hline
\end{tabular}

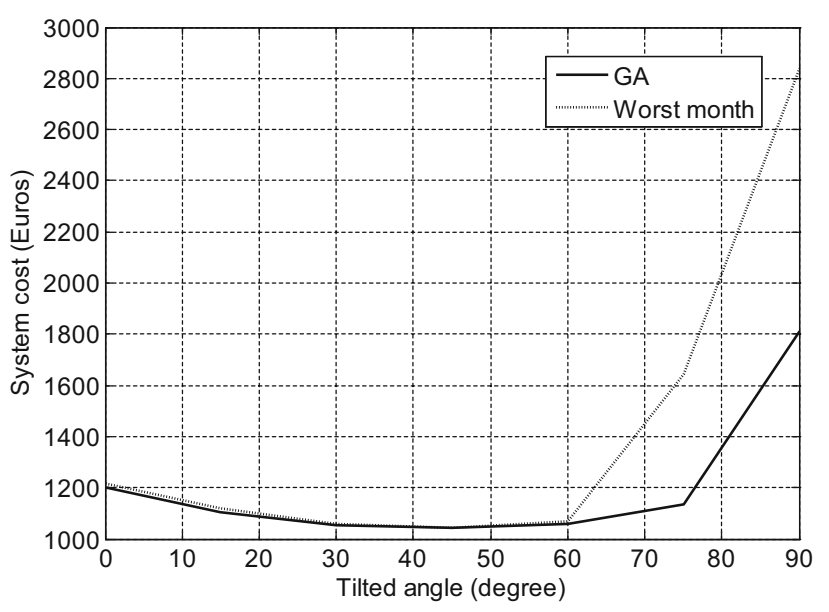

Fig. 7 Comparison between system cost obtained by the two methods

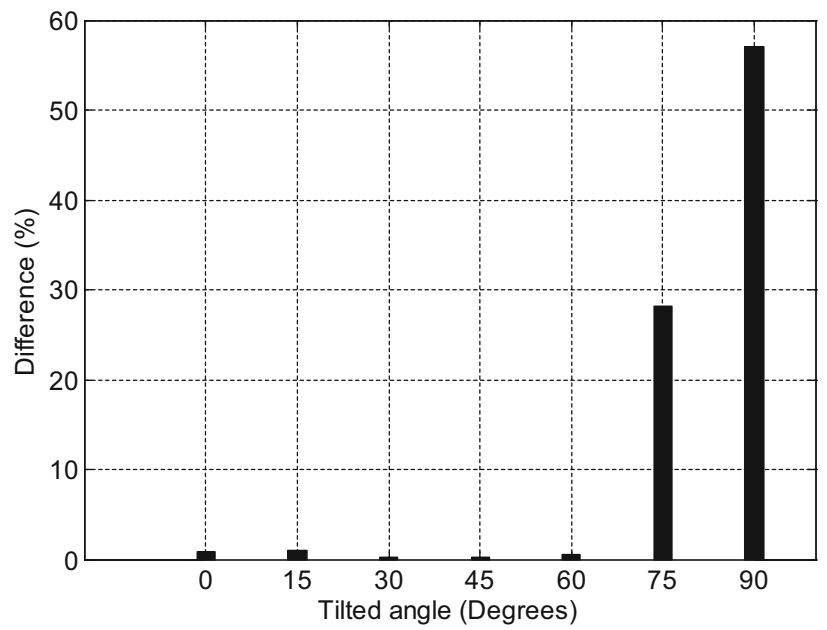

Fig. 8 Cost difference between the two methods

Results obtained for GA and worst month methods are shown in Tables 4 and 5. Figures 7 and 8 show that from $0^{\circ}$ to $60^{\circ}$ the costs obtained by the two methods are very 
close to each other and the difference is in general less than $1 \%$. Nevertheless, by increasing tilted angle above $60^{\circ}$, the difference between the two methods is very significant and GA method gives lowest cost.

Figure 9 shows PVG peak power for the two methods. It can be seen that the PVG for the classical method is

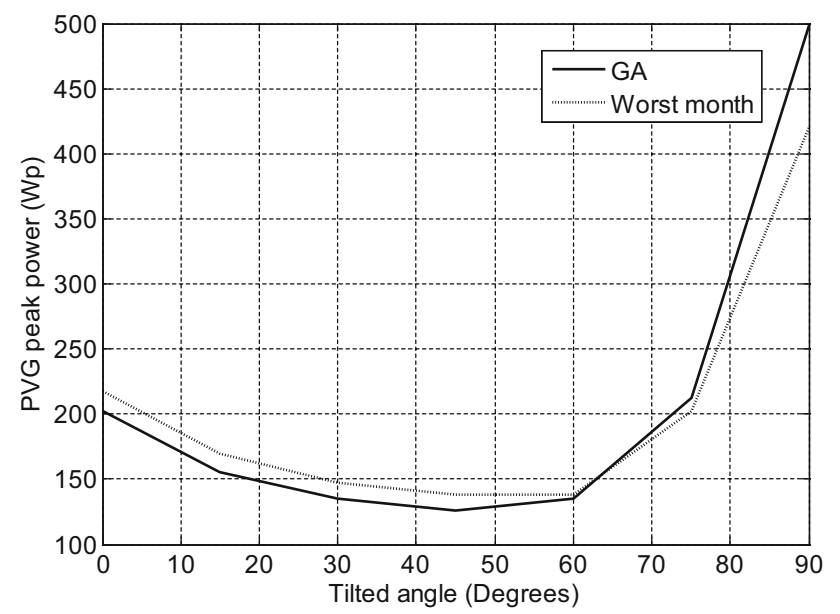

Fig. 9 Comparison of PVG peak power

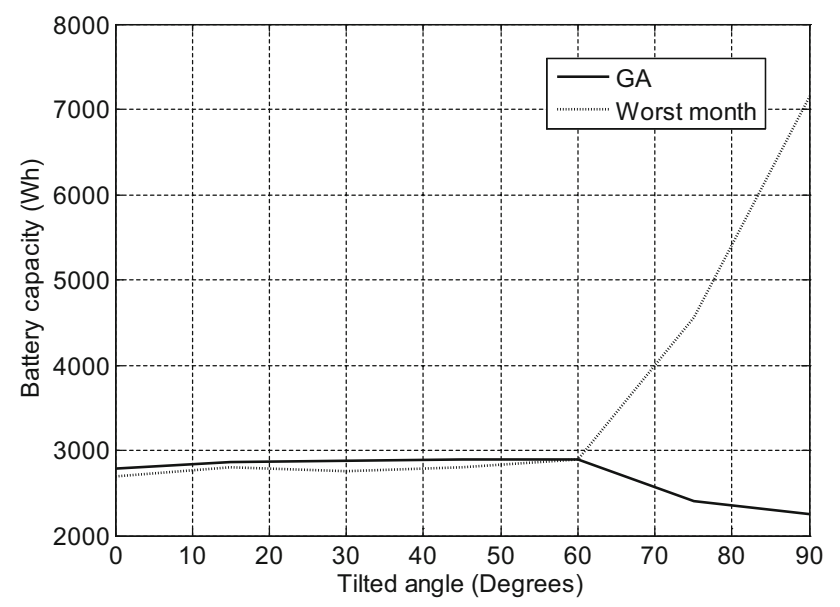

Fig. 10 Comparison of battery capacity oversized for tilted angle less than $60^{\circ}$, and undersized for tilted angle between $60^{\circ}$ and $90^{\circ}$; nevertheless the difference is not very significant between the results obtained by the two methods; except for tilted angles close to $90^{\circ}$. In general the PVG size given by the two methods is not very different and we can conclude that classical method, despite of its simplicity, gives good sizing for PVG.

Figure 10 shows battery capacity for the two methods, it can be seen that the battery for classical method is undersized for tilted angle less than $60^{\circ}$ but still not very far from optimum size given by GA method, and oversized for tilted angle between $60^{\circ}$ and $90^{\circ}$. The difference became exponential when tilted angle is over $60^{\circ}$. This result shows that the worst month method is not a good solution for sizing the battery when the tilted angle became over $60^{\circ}$.

By examining Figs. 9 and 10 it can be seen that, despite of the little difference between battery and PVG sizes given by the two methods, when tilted angle is less than $60^{\circ}$; the cost of the system obtained by the two methods still practically the same. It means that there is some possible flexibility for choosing the size of system components.

In addition, oversizing the PVG can be compensated by undersizing the battery to obtain a reasonable cost of the system. Nevertheless, undersizing the PVG has a damaging effect on total cost of the system; because it needs an important oversizing of the battery, which leads to an exaggerated total system cost.

Results given by the worst month method are obtained using an "optimum" autonomy duration. Increasing this duration will lead to an oversizing of the battery, hence to a higher cost of the system. Nevertheless, decreasing this duration will lead to an unmet load. Therefore, the most difficult task with the worst month method is the determination of the optimum autonomy duration.

Results obtained with LPSP method, with an LPSP equal to zero, are shown in Table 6 . A comparison between system cost obtained by this method and GA method is shown in Fig. 11. The results show that system cost obtained by LPSP method is much lower in comparison with GA method. Nevertheless the system is largely undersized because the unmet load calculated with the same manner as

Table 6 LPSP method Results

\begin{tabular}{lcclcc}
\hline Tilt angle $\left({ }^{\circ}\right)$ & PV generator peak power $(\mathrm{Wc})$ & Battery capacity $(\mathrm{Wh})$ & System cost $(€)$ & Unmet load $(\mathrm{h})$ & Unmet load $(\%)$ \\
\hline 0 & 73 & 870 & 378.5 & 1521 & 32.71 \\
15 & 72 & 950 & 417.5 & 1276 & 27.44 \\
30 & 74 & 1070 & 452.5 & 1139 & 1205 \\
45 & 77 & 1605 & 593.75 & 1340 & 24.49 \\
60 & 85 & 1045 & 473.75 & 1653 & 28.91 \\
75 & 96 & 1150 & 527.5 & 2470 & 35.55 \\
90 & 121 & 710 & 480 & 53.12 \\
\hline
\end{tabular}




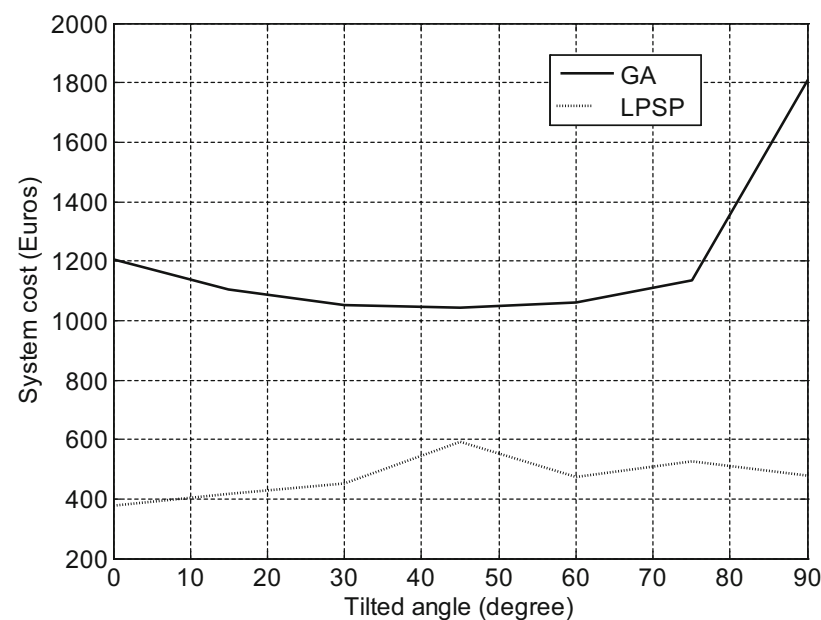

Fig. 11 Comparison between system cost obtained by GA and LPSP methods

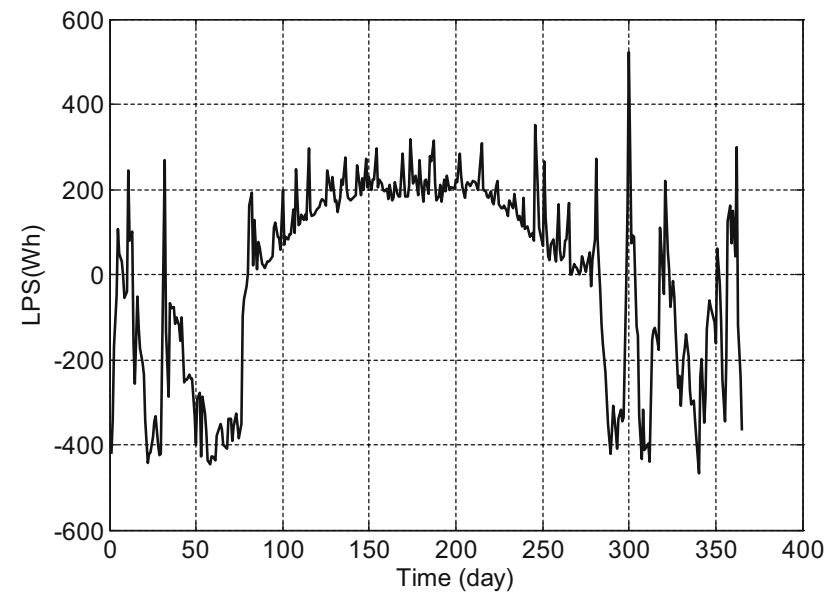

Fig. 12 Daily loss of energy supply

Table 7 Negative LPS method Results

\begin{tabular}{lllccc}
\hline $\begin{array}{l}\text { Tilt } \\
\text { angle } \\
\left({ }^{\circ}\right)\end{array}$ & $\begin{array}{l}\text { PV generator } \\
\text { peak power } \\
(\mathrm{Wc})\end{array}$ & $\begin{array}{l}\text { Battery } \\
\text { capacity } \\
(\mathrm{Wh})\end{array}$ & $\begin{array}{l}\text { System } \\
\text { cost }(€)\end{array}$ & $\begin{array}{l}\text { Unmet } \\
\text { load } \\
(\mathrm{h})\end{array}$ & $\begin{array}{l}\text { Unmet } \\
\text { load } \\
(\%)\end{array}$ \\
\hline 0 & 189 & 1690 & 895 & 51 & 1.1 \\
15 & 145 & 1825 & 818.75 & 51 & 1.1 \\
30 & 162 & 1515 & 783.75 & 32 & 0.69 \\
45 & 161 & 1470 & 770 & 31 & 0.67 \\
60 & 119 & 1980 & 792.5 & 262 & 5.63 \\
75 & 166 & 1650 & 827.5 & 424 & 9.12 \\
90 & 357 & 960 & 1132.5 & 527 & 11.33 \\
\hline
\end{tabular}

for GA method, is more than $24 \%$ for all tilt angles and reached $53 \%$ for tilted angle equal to $90^{\circ}$. This is due to the fact that this method does not take into account the load variations during a day. Figure 12 shows the daily loss of

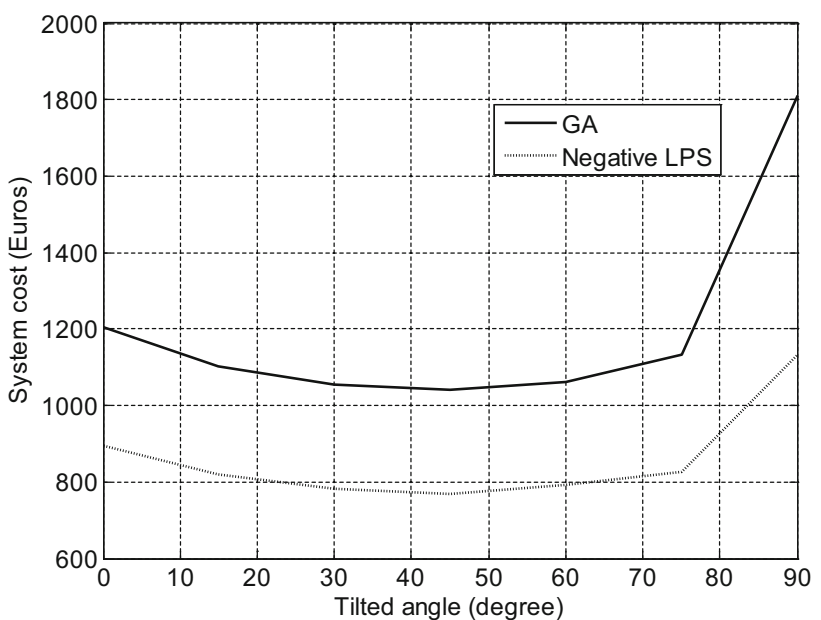

Fig. 13 Comparison between system cost obtained by GA and Negative LPS methods

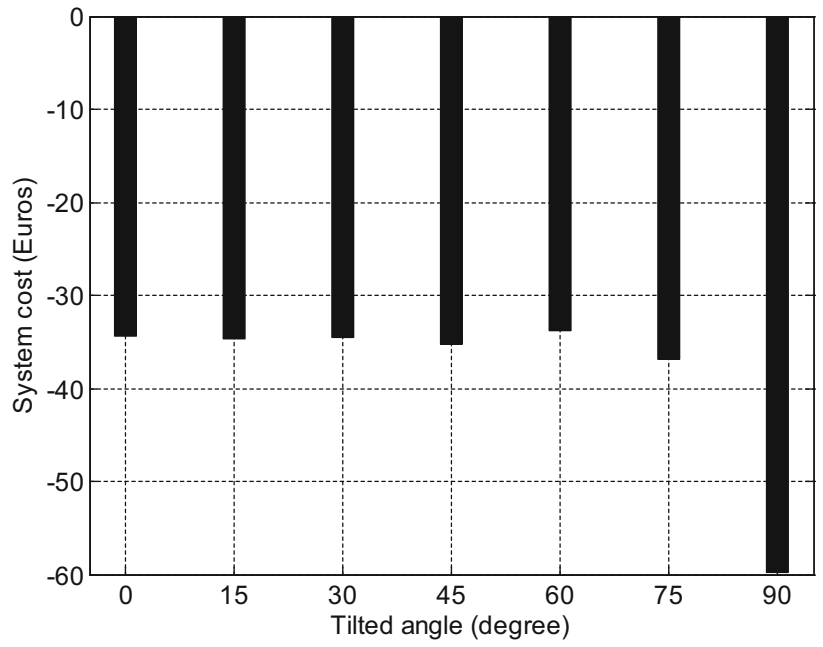

Fig. 14 Cost difference between GA and Negative LPS methods

energy supply (LPS) during a year for tilted angle equal to $90^{\circ}$. On some days, LPS is negative which means that the energy produced exceeds energy consumed. Nevertheless, in some days LPS is positive, hence the load is not met. However, integration of LPSs throughout a year gives practically zero, and hence LPSP is equal to zero, despite of large unmet load seen in Table 6 and Fig. 12.

To improve results obtained by this method, LPSP as defined in Eq. 20, has been replaced by a set of size combinations of solar array and battery those verify the following condition:

$\operatorname{LPS}(n) \leq 0 ; \quad n \in[0,365]$

Optimum size is obtained by taking the combination minimizing Eq. 18. 
The results obtained using this proposition are shown in Table 7. A comparison between system cost obtained by this method and GA method is shown in Fig. 13.

Results show that the objective of total autonomy of the system is not reached. Results for tilted angle more than $60^{\circ}$ are not acceptable because unmet load is more than $5 \%$. Figure 14 shows that with allowing minor unmet load, system cost is considerably decreased. For example, for tilted angle of $45^{\circ}$, allowing an unmet load of $0.67 \%$ decreases system cost more than $35 \%$.

\section{Conclusion}

In this study, a comparison has been achieved between a GA method and two classical methods for sizing a photovoltaic lighting system located in Adrar (Algeria).

The results obtained, by GA method and the worst month method, are very close to each other for tilted angle from $0^{\circ}$ to $60^{\circ}$. Nevertheless, by increasing tilted angle above $60^{\circ}$, the difference between the two methods is very significant and GA method gives the lowest cost. These results show that very simple method, like worst case method, can give good results under particular conditions, but the problem is to determine the adequate autonomy duration to obtain the lowest cost with non-unmet load. In this study, this duration has been obtained by trial and error process. The comparison between results, obtained by GA method and LPSP method, shows that the system is very undersized by LPSP method because the LPSP model do not take into account the load profile during one day. Therefore, to improve the results obtained with this method, LPSP has been replaced by another condition (Negative LPS). Results show that the objective of total autonomy of the system is not obtained. Results for tilted angle more than $60^{\circ}$ are not acceptable because unmet load is more than $5 \%$. In addition, by allowing minor unmet load, system cost is considerably decreased.

Author contribution statement Salim Makhloufi received his Magister degree in Electronic Engineering from the University of Batna, Algeria, his Master degree in Automatics from Ecole Centrale de Nantes, France, and his Doctorate degree from the University of Batna, Algeria in 2002, 2003 and 2013, respectively. At present, he is a lecturer at the University of Adrar, Algeria. His research interests include photovoltaic systems and intelligent control methods.

Open Access This article is distributed under the terms of the Creative Commons Attribution 4.0 International License (http:// creativecommons.org/licenses/by/4.0/), which permits unrestricted use, distribution, and reproduction in any medium, provided you give appropriate credit to the original author(s) and the source, provide a link to the Creative Commons license, and indicate if changes were made.

\section{References}

1. Wenham, S.R., Green, M.A., Watt, M.E., Corkish, R.: Applied Photovoltaics, 2nd edn. Earthscan, London (2007)

2. Luque, A., Hegedus, S.: Handbook of Photovoltaic Science and Engineering. Wiley, New York (2003)

3. Castañer, L., Silvestre, S.: Modelling Photovoltaic Systems using PSpice. Wiley, New York (2002)

4. Tamer, K., Azah, M., Sopian, K.: A review of photovoltaic systems size optimization techniques. Renew. Sustain. Energy Rev. 22, 454-465 (2013)

5. Mellit, A., Kalogirou b, S.A., Hontoria, L., Shaari, S.: Artificial intelligence techniques for sizing photovoltaic systems: a review. Renew. Sustain. Energy Rev. (2008) doi:10.1016/j.rser.2008.01. 006

6. Chen, S.-G.: Optimal sizing standalone PV systems based on the observed extremes over a threshold. In: TENCON 2010-2010 IEEE Region 10 Conference (2010). doi:10.1109/TENCON. 2010.5685875

7. Sunderan, P., Singh, B., Mohamed, N.M., Husain, N.S.: Sizing and designing a standalone photovoltaic electricity generation system using a customized simulation program. In: International Conference on business, Engineering and Industrial Applications (ICBEIA). Kuala Lumpur (2011). doi:10.1109/ICBEIA.2011. 5994234

8. Nikhil, P.G., Subhakar, D.: Sizing and parametric analysis of a standalone photovoltaic power plant. IEEE J. Photovoltaics 3(2), 776-784 (2013)

9. Spertino, F., Di Leo, P., Cocina, V., Tina, G.M.: Storage sizing procedure and experimental verification of standalone photovoltaic systems. In: IEEE International Energy Conference and Exhibition (ENERGYCON). Florence (2012). doi:10.1109/Ener gyCon.2012.6348199

10. Becherif, M., Ayad, M.Y., Hissel, D., Mkahl, R.: Design and sizing of a standalone recharging point for battery electrical vehicles using photovoltaic energy. In: 2011 IEEE Vehicle Power and Propulsion Conference (VPPC). Chicago (2011). doi:10. 1109/VPPC.2011.6043075

11. Brenna, M., Dolara, A., Foiadelli, F., Leva, S.: Urban Scale Photovoltaic Charging Stations for Electric Vehicles. IEEE Trans. Sustain. Energy 5(4), 1234-1241 (2014)

12. Hong, T. Z., Weixiang, S.: Application of genetic algorithms in the design of a solar array-exclusive standalone photovoltaic system. In: IEEE 2nd International Power and Energy Conference. Johor Bahru (2008). doi:10.1109/PECON.2008.4762518

13. Zhongshi, L., Wei, Z., Hongxing, Y.: One novel optimum sizing method for solar lighting system by using genetic algorithm. In: International Conference on Energy and Environment Technology, ICEET'09. Guilin (2009). doi:10.1109/ICEET.2009.61

14. Benhachani, Z., Azoui, B., Abdessemed, R., Chabane, M.: Optimal sizing of a solar-wind hybrid system supplying a farm in a semi-arid region of Algeria. In: 47th International Universities Power Engineering Conference (UPEC). London (2012). doi:10. 1109/UPEC.2012.6398688

15. Zaninelli, D., Leva, S.: Hybrid renewable energy-fuel cell system: design and performance evaluation. Electr. Power Syst. Res. 79(2), 316-324 (2009)

16. Iannone, F., Leva, S., Zaninelli, D.: Hybrid photovoltaic and hybrid photovoltaic-fuel cell system: economic and environmental analysis. IEEE Power Eng. Soc. Gen. Meet. (2005). doi:10.1109/PES.2005.1489546

17. Simonov, M., Musseta, M., Grimaccia, F., Leva, S., Zich, R.: Artificial intelligence forecast of PV plant production for integration in smart energy systems. Int. Rev. Electr. Eng. 7(1), 3454-3460 (2012) 
18. http://eosweb.larc.nasa.gov/sse/. Accessed February 282014

19. Goldberg, D.E.: Genetic Algorithms in Search, Optimization and Machine Learning. Addison-Wesley, New York (1989)

20. Shen, W.X.: Optimally sizing of solar array and battery in standalone photovoltaic system in Malaysia. Renew. Energy 34, 348-352 (2009)

21. Mondol, D.J., Yohanis, Y.G., Norton, B.: Comparison of measured and predicted long term performance of grid connected photovoltaic system. Energy Convers. Manag. 48, 1065-1080 (2007)

22. Townsend, T.U.: A method for estimating the long-term performance of direct-coupled photovoltaic. MS thesis, Solar Energy Laboratory, University of Wisconsin, Madison (1989)

23. Duffie, J.A., Beckman, W.A.: Solar engineering of thermal processes, 2nd edn. Wiley, New York (1991)

24. Makhloufi, S., Abdessemed, R.: Type-2 Fuzzy Logic Optimum PV/inverter Sizing Ratio for Grid-connected PV Systems: application to Selected Algerian Locations. J. Electr. Eng. Technol. 6(6), 731-741 (2011)
25. Bogdan, S.B., Salameh, Z.M.: Methodology for optimally sizing the combination of a battery bank and PV array in a wind/PV hybrid system. IEEE Trans. Energy Convers. 11(2), 367-375 (1996)

26. PVSYST V4.37 Study of photovoltaic systems (web site: www. pvsyst.com)

27. Notton, G., Poggi, P., Cristofari, C.: Predicting hourly solar irradiations on inclined surfaces based on the horizontal measurements: performances of the association of well-known mathematical models. Energy Convers. Manag. 47, 1816-1829 (2006)

28. Iqbal, M.: An introduction to solar radiation. Academic Press, Canada (1983). ISBN 0-12-373752-4

29. Owczarek, S.: Vector model for calculation of solar radiation intensity and sums incident on tilted surfaces. Identification for the three sky condition in Warsaw. Renew. Energy 11(1), 77-96 (1997)

30. www.Solardirect.com. Accessed October 122014

31. www.autokonso.com. Accessed October 122014 